\title{
BMJ Open Drivers and mediators of healthcare workers' anxiety in one of the most affected hospitals by COVID-19: a qualitative analysis
}

\author{
Mengling Fang, ${ }^{1}$ Bo Xia, ${ }^{2}$ Tian Tian, $^{3}$ Yan Hao, ${ }^{3}$ Zhenghao Wu (D) ${ }^{4}$
}

To cite: Fang M, Xia B, Tian T, et al. Drivers and mediators of healthcare workers' anxiety in one of the most affected hospitals by COVID-19: a qualitative analysis. BMJ Open 2021;11:e045048. doi:10.1136/ bmjopen-2020-045048

- Prepublication history and additional materials for this paper are available online. To view these files, please visit the journal online (http://dx.doi. org/10.1136/bmjopen-2020045048).

MF, BX and TT contributed equally.

Received 24 September 2020 Revised 28 January 2021 Accepted 02 February 2021
Check for updates

(C) Author(s) (or their employer(s)) 2021. Re-use permitted under CC BY-NC. No commercial re-use. See rights and permissions. Published by BMJ.

For numbered affiliations see end of article.

Correspondence to Dr Zhenghao Wu; 421910799@qq.com

\section{ABSTRACT}

Objective To report the driving and mediating factors of healthcare workers' anxiety during the COVID-19 pandemic.

Design Qualitative indepth interview study. Setting The Central Hospital of Wuhan, Tongji Medical College, Huazhong University of Science and Technology, Wuhan, China.

Participants 53 healthcare workers who were or were not diagnosed with COVID-19.

Results During the COVID-19 pandemic, healthcare workers were initially not sufficiently psychologically prepared. Then they suffered from severe anxiety and apprehension during the peak stage, regardless of whether they were infected with SARS-CoV-2 or not. These negative emotions were exacerbated by four drivers, namely infection risk, supplies, isolation and media. As the epidemic gradually came under control, healthcare workers experienced less anxiety from these factors, but became concerned about their low financial status. To reduce anxiety, healthcare workers diverted their attention from the risk of infection through personal entertainment and religious beliefs and focused on treating their patients. Furthermore, assistance from other people, including colleagues, families, friends, patients and society, helped protect healthcare workers from anxiety.

Conclusions Personal and social support can relieve healthcare workers' anxiety to some extent during the different stages of an epidemic. Both protective equipment and financial allowance motivate healthcare workers to focus on patient care, although the latter matters more as the epidemic comes under control.

\section{INTRODUCTION}

The COVID-19 pandemic is a global health threat and is the largest pandemic since severe acute respiratory syndrome (SARS) in 2003 The outbreak was first identified in Wuhan, China in December 2019, where early cases were reported. ${ }^{1}$ By August 2020, the total number of cases has exceeded 20 million and the number of deaths has exceeded 800000 globally. ${ }^{2}$

The Central Hospital of Wuhan (CHW) played a significant role in protecting the
Strengths and limitations of this study

- The study captured the mental health of healthcare workers during the different stages of COVID-19 in Wuhan, from an epidemic to a global pandemic.

- All participants worked at the Central Hospital of Wuhan, where six healthcare workers died due to COVID-19.

- This study included participants from multiple occupations, including doctors, nurses, and administrative and support staff, some of whom had history of infection with COVID-19, thus fully representing the views of healthcare workers.

- Although we randomly sampled healthcare workers and successfully invited most of them for the interview, some personnel refused to participate.

- Due to social distancing measures and city lockdown, many participants could not be directly interviewed through a face-to-face method, which is less effective in conveying emotions.

Wuhan people from COVID-19 invasion and sacrificed tremendously during the epidemic (figure 1). Cases in the initial cluster were associated with a seafood market in Wuhan and received treatment in the nearby Houhu District of $\mathrm{CHW}^{3}$ Before the new coronavirus was discovered, healthcare workers at CHW were fully exposed to infected patients without enough knowledge and sufficient personal protective equipment (PPE). On 30 December 2019, the test results of a patient showing high confidence level for SARS coronavirus infection were announced to the public by Dr A of CHW, who thus was called the 'whistleblower'. Unfortunately, Dr A was later diagnosed with COVID-19 and died after 5 days. Similar to Dr A, another five doctors at CHW died due to COVID-19-associated complications. They are all honoured as heroes in China.

Since December 2019, healthcare workers in Wuhan, China had to treat patients with COVID-19 with increased workload and risk 


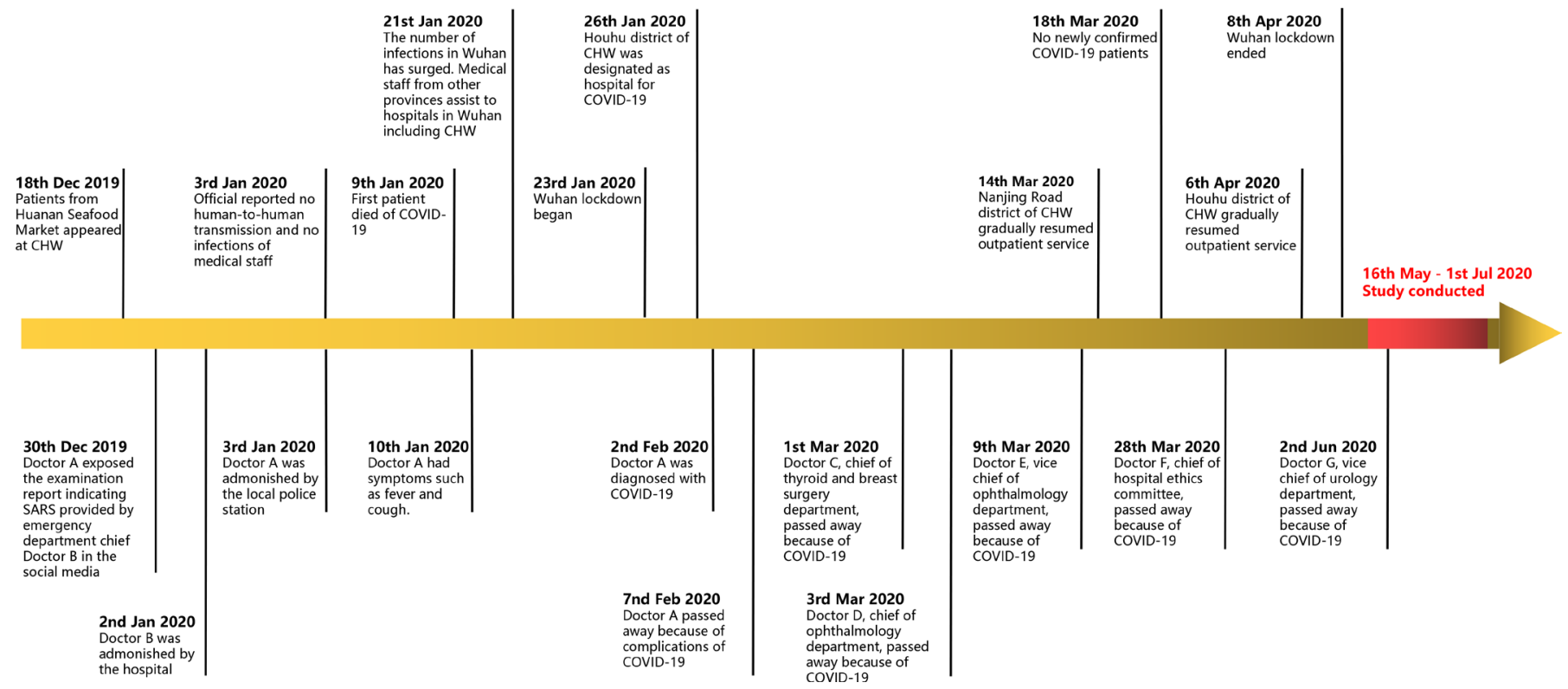

Figure 1 Milestone events in the Central Hospital of Wuhan (CHW) during the COVID-19 pandemic. SARS, severe acute respiratory syndrome.

of infection. SARS-CoV-2 had high transmissibility in Wuhan before the travel restrictions, with the median daily reproduction number (Rt) of the virus estimated at 2.35. ${ }^{4}$ In a Wuhan hospital case series, a super-spreader was confirmed to transmit SARS-CoV-2 to more than 10 physicians and nurses in the department. ${ }^{5}$ As the epidemic progressed and cases increased, healthcare workers were recognised as a group at high risk of infection. By 8 March 2020, 1496 healthcare workers were diagnosed with laboratory-confirmed COVID-19 in Wuhan, China, a large part of whom worked at $\mathrm{CHW}^{3}{ }^{3}$ Healthcare workers had shown professionalism and care; however, their physical and psychological health came under pressure when working t high risk of infection.

Multiple studies have explored the mental health of hospital staff using questionnaires. It has been reported that more than half of healthcare workers experienced depression and distress symptoms. ${ }^{6}$ Nurses, women and front-line staff had worse mental health than others. ${ }^{67}$ Social support could help healthcare workers reduce their anxiety and stress and improve their sleep quality. ${ }^{8}$ In the above quantitative research using questionnaires, the respondents were only allowed to answer predefined questions. For individual participants, questions not covered by the questionnaire might be highly relevant and therefore missed. Moreover, questionnaires do not allow personalised thoughts and feelings on the subject. ${ }^{9} 10$ Qualitative research constitutes a feasible complement to an indepth exploration of a phenomenon.

To understand the obstacles that healthcare workers encounter when performing epidemic control tasks, we conducted indepth interviews using qualitative design. This study aimed to make an indepth exploration to (1) describe the mental status of healthcare workers during the COVID-19 pandemic; (2) identify the main factors that upset healthcare workers; and (3) characterise how the medical staff are relieved of pressure.

\section{METHODS \\ Design and patients}

Qualitative research was conducted among workers at CHW between 16 May and 1 July 2020. Study participants were eligible if they worked at CHW during the epidemic. All types of workers at CHW, including doctors, nurses, and administrative and support staff, were sampled for the study. By using these separate groups, we aimed to improve trustworthiness of data.

Participants were selected through purposeful maximum variation sampling regarding age, sex, occupation and working position in order to achieve full coverage. The number of participants was determined based on 'saturation', a sense of closure that occurs when data collection ceases to provide important new information and patterns in data become evident. During the study, saturation was achieved after 38 interviews. To accomplish maximum variation, interviews continued with further participants to ensure that no new aspects emerged. In total, 53 healthcare workers completed the full research, with a participation rate of $69.7 \%$ (53 of 76) based on the total number of individuals whom we invited to interview. All participants who accepted our invitation finished the full interview. To fully inform participants of all relevant information and risks of this research, formal informed consent was provided to all participants before the interview. At the beginning of the interview, all participants acknowledged that they had read this informed consent and fully understood the research. 


\section{Data collection}

All researchers participated in the interview. Researchers had experience in qualitative interviews and underwent training from tutors with psychological consultant certificates issued by the Ministry of Human Resources and Social Security of China. They also worked at the front line during the COVID-19 pandemic and empathised with other healthcare workers. Therefore, researchers were able to carry out interviews independently. Data were gathered by semistructured interviews mostly through phone or internet communication tools such as WeChat and QQ due to social distancing measures. All audio interviews were recorded and transcribed verbatim with participants' permission. Demographic data collected included age, gender, departments, professional titles, educational background, marriage status, occupation, working life and history of COVID-19.

The interview guide included questions regarding the experience of living and working during the pandemic and was designed with the help of professional qualitative researchers and distributed to interviewers with associated experience (online supplemental file 1). The following are examples of the initial questions: 'What did you experience during the epidemic?', 'How did you feel when you heard of your colleagues' death?', 'Has something changed after epidemic?' When needed, follow-up questions were posed. The interviews were carried out by at least one interviewer and lasted for 10-60 min. Six interviews were repeated more than once to clarify critical questions.

\section{Data analysis}

Data were analysed by a team of three trained qualitative researchers based on Hsieh and Shannon's conventional content analysis method. ${ }^{11}$ Hsieh and Shannon's ${ }^{11}$ approach is generally used with a study design to describe a phenomenon, in this case healthcare workers' emotional reactions during the COVID-19 pandemic. The advantage of Hsieh and Shannon's approach is gaining direct information from study participants without imposing preconceived categories or theoretical perspectives. Researchers immerse themselves in interview data content to allow new insights to emerge ${ }^{11}$ First, the interviews were read through several times to become acquainted with the content. They were then reread systematically to identify meaning units, such as words or text segments and patterns of meaning, which were also marked with a preliminary code. The team developed a structured codebook that included inductively derived codes that represented ideas that emerged from the data as well as deductively selected categories to organise the data set. Second, the investigators conducted multiple rounds of codebook revisions and inter-rater reliability testing until a minimum pooled kappa value greater than 0.8 was achieved by all coders to ensure clarity of coding definitions. Periodic discussions among the investigators ensured consistency of coding and helped reach an agreement on codebooks. Third, segments marked with similar codes were brought together and formed meaningful clusters, and as much as possible the actual words expressed by the informants were used. Next, each cluster's statements were scrutinised and compared to identify the central component and were then combined into categories. The final categories were then compared to avoid obvious overlapping. In the last step the categories were compared and analysed to reveal possible relationships or hierarchies between them.

All participants were native Chinese speakers, so all interviews were conducted in Chinese. To cite the interviewees' words in this paper and completely convey their semantics, investigators and native English speakers cooperatively translated these excerpts to English. This study is reported in accordance with the Consolidated Criteria for Reporting Qualitative Research checklist. ${ }^{12}$

\section{Trustworthiness}

Trustworthiness is the standard that constitutes the rigour of qualitative research. ${ }^{13}$ During the interviews, similar questions were put in different ways to ensure that the informant's views were correctly captured. Then coauthors reviewed and commented on relevant interview transcripts separately and discussed their findings through continuous communications. To promote reflexivity during analysis meetings, team members discussed their insights and perceptions and potential biases to make sure they were accounted for in the data interpretation. ${ }^{13}$ Then interpreted results were sent to participants via email for comments or corrections to ensure their opinions were accurately reflected in the data and to check consistency between the results from the researchers and the actual intentions of the participants. ${ }^{14}$ Dependability is achieved through accurate records and indepth descriptions of the methods used in the research. In terms of transferability, we used a detailed description method to ensure sufficient and accurate contextual information. The findings and conclusions can be transferred to other studies with similar situations. The quotes from the interviews are also provided as examples to clarify the explicated meanings and establish validity.

\section{Patient and public involvement}

No patients were involved in this study. Summary results were sent to participants via email for feedback and comments before publication.

\section{RESULTS}

Altogether, 53 healthcare workers were interviewed, with age ranging from 23 to 63 years (mean=39 years), and 32 $(60.4 \%)$ participants were women. Eighteen healthcare workers were infected with COVID-19, and 40 participants treated patients with COVID-19 at the front line. All participants were working at CHW during the pandemic (table 1).

The issues and connections were extracted from all interview data and summarised in a conceptual model, 
Table 1 Demographic and occupational characteristics of interviewees

\begin{tabular}{|c|c|c|}
\hline & & $\mathbf{n}$ \\
\hline Number of interviewees & & 53 \\
\hline Gender & Male & 21 \\
\hline & Female & 32 \\
\hline Age, years & Range & $23-63$ \\
\hline COVID-19 infection & Yes & 18 \\
\hline & No & 35 \\
\hline Working position & Front line & 40 \\
\hline & Second line & 13 \\
\hline Working life, years & Range & $1-32$ \\
\hline Occupation & Physician & 18 \\
\hline & Nurse & 24 \\
\hline & Others in hospital & 11 \\
\hline Marriage status & Unmarried & 33 \\
\hline & Married & 20 \\
\hline Educational background & $\begin{array}{l}\text { Undergraduate or } \\
\text { lower }\end{array}$ & 36 \\
\hline & $\begin{array}{l}\text { Postgraduate or } \\
\text { higher }\end{array}$ & 17 \\
\hline
\end{tabular}

which was composed of healthcare workers' anxiety during the different stages of the pandemic and related drivers and mediators (figure 2).

Healthcare workers' anxiety during the different stages of the epidemic

Healthcare workers experienced a process of dynamic changes in emotions during the entire epidemic, which was divided into three stages.

At the initial stage of the epidemic, most participants experienced few intrusive and frightening thoughts about their clinical work because they did not understand the severity of COVID-19. In January 2020, the Wuhan government released a statement that 'No clear evidence of human-to-human transmission was found. Therefore, this epidemic is preventable and controllable', which resulted in some participants losing their vigilance. However, participants from departments such as respiratory, infection and emergency departments, who were more likely to be exposed to patients with pneumonia, noticed a new kind of emerging respiratory disease and therefore were more vigilant and worried ahead of other healthcare workers.

At the beginning of the outbreak, I felt nothing because it had not happened besides before. I was not scared until people around me were infected. -26

In the early stage of the epidemic, the emergency department staff was all transferred from other departments. The team leader was isolated because of the abnormal CT examination results, and she only taught me one day. Other nurses without enough professional skills often sat beside the consultation desk outside, and only I worked in the rescue room. Everyone was lazy and didn't want to do anything. $-29$

Hmmm... In December, patients with similar symptoms (to COVID-19) appeared in our department. At that time, we were quite anxious. Although the number of cases increased in January, people from other departments came to support us, and more protective equipment was provided to us, so the situation is much better. By this time, we became accustomed to this state. - 31 (nurse, respiratory department)

As the epidemic progresses to its highest peak, almost all general practitioners in the hospital experienced the infection or death around, including patients, colleagues

Figure 2 Conceptual model of themes and relationships derived from healthcare workers' anxiety during the different stages of the pandemic. 
and even themselves. They began to realise the seriousness and severity of the epidemic. Most of our interviewees were overflowing with intense negative emotions, such as 'desperation', 'depression', 'fear' and 'anxiety', after they heard or witnessed their colleagues being infected with COVID-19 and worried about their health.

So desperate, there was definitely a desperate mood, most desperate in 6th Feb (when Dr. A passed away)... it's not suitable for elaboration... such famous ones are not cured. If me... - 41

At first, I didn't know it was COVID-19, so I wasn't afraid. Later, after a large number of patient cases were reported on the internet, I began to get scared. $-50$

When I heard that the doctor in our hospital died, I was scared and wanted to cry. (silence). I don't know how to describe it. -13

Very unreal feeling, kind of unbelievable, after all, they (doctors who died of COVID-19) were working with me before. I can't believe this news is true! -15

My family members were very worried about me and called me every day. Although I worried about myself, I was more scared about whether my family members would be infected. - 36

As time went by, people gradually recovered to calmness and pursued the tranquillity of a postvirus life. Most front-line workers had gradually adapted to this state of work, with increasing cases being cured and good news being reported by the media. However, after the Wuhan lockdown ended and outpatient services were opened, the number of patients had dropped sharply compared with before the epidemic, and so healthcare workers' wages also decreased, causing more stress to participants who also need to repay loans. However, some participants were unwilling to mention what happened during the COVID-19 epidemic and committed to new careers to minimise anxiety and pretend fearlessness.

I'm very sorry. (silence) My comrades fighting side by side are gone forever. Strongly grieved for their families! I wanted to do something for them, so I participated in donations and contacted related foundations. -4

About the occupation, the COVID-19, others' death... I didn't think deeply. Not dare to. I just wanted to have a good day every day. -16

Nevertheless, several interviewees did not seem to experience any emotional fluctuations from beginning to end, probably due to personal temperament and working experience.

When doctors in our hospital passed away, I was not afraid at all. I only had two choices, either survive or die. I didn't care. —42 (infected doctor)

I experienced many ups and downs in my whole life. This epidemic was only one of the difficulties. I was not afraid, because I participated in the fight for SARS in Guangzhou in 2003 - 17 (second-line doctor)

\section{Drivers of healthcare workers' anxiety}

This category was developed to capture the underlying causes of participants' anxiety during the different stages of the pandemic in five themes.

\section{Infection risk}

SARS-CoV-2 is spread mainly through aerosolised droplets expelled during coughing, sneezing or breathing, with a robust transmissibility. ${ }^{4}$ Healthcare workers have been particularly hard hit by SARS-CoV-2, with high reported infection rates from Italian data. Even a high percentage of asymptomatic healthcare workers were reported to test positive for SARS-CoV-2 according to PCR results. ${ }^{15}$ Their anxiety was related to, and triggered by, examinations and treatments of confirmed and suspected patients as there was always the potential risk of infection. After getting off work and staying away from patients, the level of anxiety temporarily decreased, but increased again close to the next day at the hospital. Participants' anxiety towards risk of infection mainly occurred at the peak of the epidemic and gradually disappeared as the epidemic came under control.

At that time, I was crying with my roommate at home every day. In fact, I got only an ordinary lung infection. -19

Everyone could be infected, and I was no exception. $-25$

Scared! I was really terrified! I was really afraid of getting infected. The isolation wards were full of COVID-19 confirmed patients. - 3

\section{Supplies}

After the COVID-19 outbreak, the government imposed a strict lockdown in Wuhan and many living supplies were difficult to obtain. Furthermore, the healthcare workforce's need for PPE such as surgical masks and isolation gowns outpaced the supply during the early onset of COVID-19. Adequate supplies of PPE among healthcare workers were identified as an effective protective strategy against the psychological distress caused by the emerging virus outbreak. ${ }^{16}$ Participants without enough PPE worried about the high risk of infection for themselves and their families. Therefore, communities and governments provided adequate supplies to alleviate shortage and minimise burden among clinical staff.

After job transfer from respiratory medicine to CCU, no one cared about me. Totally helplessness. I couldn't get living supplies such as rice and noodles and buy food (because of lockdown in Wuhan). - 51

Living and protective supplies are sufficient. When everyone in the hospital was scrambling for supplies, a friend knew my situation and sent me two food boxes with bread and milk. I thought Wuhan was quite lovely at that time. - 34 
Because of fundraising from all over the country and even around the world, healthcare workers including me were not short of living supplies, but my family still lacked supplies. During this period, I was more worried about my family than myself. -15

\section{Isolation}

WHO recommended that healthcare workers suspected of COVID-19 who present with mild or moderate symptoms should be encouraged to stay home and away from workplace during illness. ${ }^{17}$ It has been reported that individuals, including healthcare workers, who self-isolated at home suffered from increased anxiety and stress. ${ }^{18}$ Participants felt 'so lonely as if abandoned by the world' and 'be seemingly treated like a criminal' during the quarantine. In contrast to depression brought about by isolation, some participants prefer to treat patients and continue with clinical work despite the high risk of infection.

At the beginning of the epidemic, I was under a lot of psychological pressure. There was something wrong with the CT examination of the roommate's lungs, so I was also isolated at home. - 49

I'm afraid of isolation. No matter how good the environment is, I can't accept isolation. I am willing to work in the hospital rather than being isolated. In order not to be isolated, it is necessary to rest well and boost immunity. -22

\section{Media}

Although WHO has produced guidance for opinionmakers and the media on how to describe the outbreak, few local and social media strictly obeyed this guidance during the initial stage of the epidemic, causing more stress to healthcare workers. ${ }^{19}$ For example, some media presumed the possibility of healthcare workers having or spreading COVID-19 rather than highlighting the effectiveness of preventive measures, and therefore some people worried about contact with neighbours working in hospital.

In addition, many healthcare staff learnt about the infection or death of their colleagues through social media, and mourn their loss and also get scared of being infected. An interviewee quoted a Chinese colloquialism to express her sorrow: "The fox mourns over the hare's death.”

During the epidemic, I lived in a hotel close to the hospital rather than at home. The management company in my community was not willing to allow me to enter it after hearing that many doctors in our hospital were infected. -37

When I was treated for COVID-19, all kinds of bad news appeared, especially which doctors in our hospital passed away. (Appeared surprised) I tried not to watch bad news, but It was impossible to block social media from all my friends. After reading them, I was afraid that I would not be cured. Therefore, when the doctor told me to use the immunity-enhancing drugs at my own expense, and I said: 'use them, no matter how much they cost'. -53

\section{Financial status}

During the peak of the epidemic, healthcare workers received an allowance from the government for treating patients with COVID-19. The government reimbursed people infected with COVID-19 in China for all treatment costs, and infected healthcare staff can also claim workers' compensation insurance. Therefore, few healthcare workers were anxious about their financial status during the peak of the epidemic. However, at the end of the Wuhan lockdown and the opening of outpatient services, when the epidemic came under control, participants complained that salaries were not satisfactory because the government cancelled their allowances and patients were unwilling to visit the hospital due to fear and risk of infection, decreasing hospital profits. Some interviewees also felt that their efforts and sacrifice had not been reasonably compensated and were eager to obtain adequate financial rewards.

Will my salary be raised in the future? It is too low to support myself now. - 30

But I think we are really the cheapest labor force because I met my classmates on Sunday, they worked in Didi (a taxi company) and drove medically equipped vehicles during the epidemic? They earned more than 100,000 yuan $(\$ 14,000)$ in a single week! They really made more than 100,000 yuan! But how much for us? really cheap labor! —21

\section{Self-mediators of healthcare workers' anxiety}

In the face of high occupational risk, healthcare workers developed their own way to protect themselves from anxiety and depression.

\section{Occupational attitude}

Most healthcare staff who decided to take up medicine as a career tended to endorse altruistic reasons (working with people, helping others) rather than the possibility of achieving high social status and financial stability. ${ }^{20}$ Under the threat of COVID-19, participants identified the desire to rescue patients as a motivation.

The doctors' duty is to heal the wounded and rescue the dying. - 41

I never thought of resignation and still have fullhearted enthusiasm. Many colleagues returned to work immediately after recovery from COVID-19. $-33$

Everyone has their own responsibilities in their positions. I have a clear conscience only if I do my best. $-17$

\section{Fitness}

A high level of cardiorespiratory fitness caused by prior exercise training reduces all-cause mortality and may confer some protection against COVID-19. ${ }^{19}$ Two infected 
participants were in satisfactory physical condition before and had a strong belief of being cured from COVID-19. In addition, younger age patients were identified with good prognosis, which boosted some young participants. ${ }^{21}$

There is no special medicine for COVID-19. It's totally dependent on your immunity. I always exercised before, so I wasn't injected with immunoglobulin while being infected. -28

I limited energy intake to lose weight before. However, my workload suddenly increased, and I need to maintain a proper diet to supplement nutrition after the COVID-19 epidemic. —52

\section{Entertainment}

Entertainment such as videos, computer games and other personal hobbies at home has considerable potential to relieve healthcare workers of pressures of reality. Several interviewees indulged in personal hobbies to escape from work fatigue and anxiety about their relatives' health.

My boyfriend gifted me a microphone, and I sang at home. Later, I felt that I couldn't stand it and applied for a photography class at home. There is always something to do, in case I thought so much. -14

Eat, drink, and sleep when I should. Watch TV drama or play video games when I'm free. - 11

When I was hospitalized, I played 'Honor of Kings' (a mobile MOBA game) every day. —32

\section{Religion}

Only one participant used religious beliefs to avoid negative moods when under the pressure of frequent infections of companions. During the pandemic, places of worship such as temples, churches, synagogues and mosques were also closed in Wuhan, which interrupted most of the religious activities. Therefore, she sought spiritual peace by 'copying the Buddhist sutras at home'.

After I got off work, I copied the Buddhist sutras at home. The power of religious belief has always supported me. - 29

\section{Interpersonal mediators of healthcare workers' anxiety}

Faced with successive deaths of patients and colleagues, many participants experienced heavy psychological pressure and sought help from other people, including colleagues, families, friends, patients and society (table 2).

During working hours, colleagues and companions played a significant role in relieving loneliness and horror. Participants 'rushed to the front' similar to soldiers and treated their colleagues as comrades-in-arms. Some infected interviewees experienced a dramatic change of identity from doctors/nurses to patients and desired more psychological support from their health carers and colleagues. In addition, patients also expressed their gratitude to some participants for their dedication. After getting off work, most participants felt less anxious and depressed by communicating with their families and
Table 2 Interpersonal mediators of healthcare workers' anxiety

\begin{tabular}{ll}
\hline Theme & Exemplary quotes \\
\hline Colleagues & "Many colleagues are rushing to the front, so I \\
& have no reason to back down." -36 \\
& "None in my family was infected, because a \\
& teacher in our department is very cautious. \\
& Before the New Year, when the epidemic was \\
& not exposed to the public, she already told \\
& me some precautions, such as keeping social \\
& distance and dining with public chopsticks." \\
& -48 \\
& "When I was diagnosed as CoviD-19 and \\
& hospitalized, there were still very few beds. The \\
& chief nurse reported my situation to the public \\
health department and arranged a bed for me. & Doctors and nurses were very kind, maybe \\
because we worked together." - 44 \\
"Daily video with my family. I told them I am \\
much better now and what medicine I used \\
today. When I was dining outside the ward, I \\
took down my mask and showed them that I \\
was okay. In the later period, when I was about \\
to be discharged from the hospital, they were \\
completely relieved." - 6 \\
"My deepest thought (when I was infected and \\
hospitalized)? I have my wife and my family. I \\
must live a very healthy life. I still look forward \\
to living in this world." - 7
\end{tabular}

$\begin{array}{ll}\text { Friends } & \text { "I once collapsed. There were only three or } \\ \text { five COVID-19 confirmed patients every day } \\ \text { before. However, the number increased by } \\ \text { tens of thousands those days, and I couldn't } \\ \text { bear it. But I couldn't tell my mother because } \\ \text { she would be more worried and sleepless. So } \\ \text { I talked with my friends, which made me feel } \\ \text { better." }-3 \\ \text { "When I was upset, I talked to my good friend } \\ \text { and complained about something." - 37 } \\ \text { "The lady who lived beside my bed was kind to } \\ \text { me. She was always comforting me. She said: } \\ \text { 'Although I had a basic illness like diabetes, I } \\ \text { am much better now. The effusion of my lungs } \\ \text { is almost absorbed.' Her words made me } \\ \text { feel much better. I was so lucky that she was } \\ \text { always encouraging me and chatting with me." } \\ \text { - } 41\end{array}$

friends, who always encouraged them to hold on. Participants' families relieved them of their negative emotional state through encouragement, care and comfort. Sometimes, participants were unwilling to share their anxiety 
with their families 'because the family would be more worried and sleepless'. Furthermore, the government and hospital provided living and protective materials 'as much as possible', which were indispensable to living during the epidemic and lockdown in Wuhan.

\section{DISCUSSION}

Our research divided the COVID-19 epidemic-pandemic as experienced by healthcare workers into three stages and tracked the dynamic changes in their mental state. While these emotions may be mitigated or exacerbated by work experience, environment and health status, participants' reports suggest these experiences are pervasive. Eftekhar Ardebili et a $t^{22}$ showed how emotions and feelings developed with the time of evolution of the pandemic. These authors developed a three-level model: early exposure, with high levels of fear, anxiety and loss of control; peak of the crisis, which featured feelings of helplessness, hopelessness and depression; and long-term effects, with symptoms of post-traumatic stress disorder (PTSD) and reappearance of fears. Compared with Eftekhar Ardebili et $a l \mathrm{~s}^{22}$ model, we found that during early exposure most participants had no sense about the COVID-19 epidemic and thus experienced few negative emotions. However, they tremendously suffered psychological pain during the peak of the crisis with massive infections and deaths of patients and colleagues. A faster emotional shift was observed in our research than in other reports.

To date, most reported qualitative research has focused on the emotional experiences of healthcare workers during the peak of the COVID-19 pandemic. ${ }^{23-25}$ All research found that the pandemic outbreak led to a series of negative emotions, such as depression, anxiety and fear. ${ }^{23-25}$ However, in different studies these psychological symptoms were attributed to different driving factors. Some participants were plagued by job challenges, such as inappropriate clinical scheduling, inadequate capacities for difficult tasks and insufficient cooperation with community workers. ${ }^{24} 25$ They also sympathised with patients' suffering and felt upset for their incapability of curing dying patients. ${ }^{2325}$ Zhang $e t a^{26}$ reported that nurses experienced negative emotional reactions during the initial period of home isolation. During social distancing and isolation, residents felt psychological and emotional loss, criticised government communication, adhered to social distancing guidelines, and were uncertain about social reintegration and the future. ${ }^{27}$ In addition, the risk of viral infection and the shortage of protective devices distressed many healthcare workers. ${ }^{22} 2325$ Aside from these factors, our conceptual model also illustrates the media's role in triggering emotional responses.

Few studies have explored healthcare workers' emotional experiences during the late period of the epidemic. Notably, the level of anxiety of participants did not significantly decrease with complete control of the epidemic in Wuhan, which was attributed to not only PTSD but also poor postepidemic financial status.
Most participants explicitly or impliedly expressed their concerns and dissatisfaction with their income, which has never been mentioned in other research. Therefore, strategies to help healthcare workers overcome challenges and prevent the primary care system from being overwhelmed are continuously needed in the long fight against COVID-19. Health authorities and institutional leaders are expected to provide both mental and material support to healthcare workers.

It has been reported that groups at high risk of mental health symptoms include nurses, women, frontline healthcare workers and those working in Wuhan, China, which accounted for $35 \%$ of interviewees in this study. ${ }^{6}$ Notably, most of our interviewees never worked in respiratory, infection, emergency, intensive medicine and other related departments before the COVID-19 pandemic. Therefore they experienced more perceived stress and less social support when treating patients with COVID-19. ${ }^{28}$ In addition, our research population came from a particular hospital in Wuhan where the COVID-19 epidemic first broke out, and more medical workers died there due to infection compared with all other hospitals. Chinese and even the world media focused on workers' status in this hospital during the epidemic. Due to tremendous pressure from multiple factors, healthcare workers might have suffered from more serious anxiety than those from other hospitals. Thereby, they represent majority of healthcare workers worldwide who were under severe psychological stress during the pandemic.

Our findings extend research on mental health in the medical workplace during a public crisis and provide a view of death anxiety directly from the perspective of those who experienced it. Death anxiety is a multidimensional construct that involves cognitive, emotional and experiential aspects. ${ }^{29}$ It has been reported that physicians' death anxiety for patients did not relate to decision making during clinical treatment, but guilt or doubt after a patient's death. ${ }^{30}$ However, few studies have focused on physicians' death anxiety for their colleagues, which had a huge negative impact on health professionals. Participants in our study revealed significantly reduced enthusiasm and efficiency at work due to colleagues' infection and death. When healthcare workers saw their colleagues bearing the hardship, they were inspired to show greater solidarity and cohesion. As for participants infected with COVID-19, they reported concerns about fear of dying alone and being separated from their loved ones, fear of infecting their families, friends or colleagues, and fear of stigmatisation. $^{22}$

Healthcare providers had multiple ways to recover from affliction, not only by self-management strategies but also by social support systems, including colleagues, families, friends, patients and society. With logistical support from their hospital and encouragement among colleagues, they developed a sense of safety and felt they were not alone. ${ }^{23}$ In addition, the local government and hospitals had predicted high mental pressure among healthcare workers in advance and offered them professional 
psychological counselling and related questionnaires. ${ }^{31}$ Nevertheless, no participants expressed benefits from these measures, indicating these psychological interventions were invalid and insufficient to alleviate psychological issues.

Some limitations need to be considered when interpreting our findings. First, the timing of administering the interviews might affect the results. The participants likely had less anxiety because they were assured they would not be infected with COVID-19 due to the well-controlled epidemic in Wuhan. Second, all participants voluntarily took part in the research. Although we randomly sampled healthcare workers and successfully invited most of them to the interviews, some personnel who suffered severely were less inclined to participate. Finally, due to social distancing measures and city lockdown, many participants could not be directly interviewed through a face-to-face method, which is less effective in conveying emotions. To catch participants' faces and actions, video calls and online conference apps were recommended if permitted by interviewees.

\section{CONCLUSION}

Our research reports a comprehensive conceptual model to describe the cause and regulation of anxiety among healthcare workers during the different stages of the pandemic and raises questions about psychological and physical protection measures. Although the government and the society provide materials and spiritual support as much as possible, most healthcare workers still felt neglected and anxious about the risk of infection and their income level. Psychological intervention and personal protection among healthcare workers need to be immediately carried out especially in districts and hospitals seriously affected by COVID-19. Healthcare workers in epidemic-controlled districts are at low risk of infection but also lower income and so can benefit more from financial compensation.

\section{Author affiliations}

${ }^{1}$ Department of Cardiology, The Central Hospital of Wuhan, Tongji Medical College, Huazhong University of Science and Technology, Wuhan, Hubei, China ${ }^{2}$ Operating Room, The Central Hospital of Wuhan, Tongji Medical College, Huazhong University of Science and Technology, Wuhan, Hubei, China

${ }^{3}$ Department of Digestion, The Central Hospital of Wuhan, Tongji Medical College, Huazhong University of Science and Technology, Wuhan, Hubei, China ${ }^{4}$ Department of Breast and Thyroid Surgery, Union Hospital, Tongji Medical College, Huazhong University of Science and Technology, Wuhan, Hubei, China

Acknowledgements We are grateful for all participants who took the time to give an interview during busy times. We thank all healthcare workers in the CHW for treating COVID-19 patients in the front line. Furthermore, we thank the assistance of Prof. Jiwen Chen for assistance with development of this project.

Contributors MF and ZW conceived of the study and analysis plan. MF, BX, TT and $\mathrm{YH}$ collected the data. MF and ZW analysed the data. ZW drafted the conceptual model. MF and ZW wrote the first draft of the manuscript. All authors contributed to the interpretation of the data, edited the manuscript and approved the final manuscript. ZW had full access to all data in the study and had final responsibility for the decision to submit for publication.
Funding The authors have not declared a specific grant for this research from any funding agency in the public, commercial or not-for-profit sectors.

Competing interests None declared.

Patient consent for publication Obtained.

Ethics approval This study was conducted in accordance with the Declaration of Helsinki. All participants agreed to participate. The Central Hospital of Wuhan Ethics Committee approved the study procedures.

Provenance and peer review Not commissioned; externally peer reviewed.

Data availability statement Data are available upon reasonable request.

Supplemental material This content has been supplied by the author(s). It has not been vetted by BMJ Publishing Group Limited (BMJ) and may not have been peer-reviewed. Any opinions or recommendations discussed are solely those of the author(s) and are not endorsed by BMJ. BMJ disclaims all liability and responsibility arising from any reliance placed on the content. Where the content includes any translated material, BMJ does not warrant the accuracy and reliability of the translations (including but not limited to local regulations, clinical guidelines, terminology, drug names and drug dosages), and is not responsible for any error and/or omissions arising from translation and adaptation or otherwise.

Open access This is an open access article distributed in accordance with the Creative Commons Attribution Non Commercial (CC BY-NC 4.0) license, which permits others to distribute, remix, adapt, build upon this work non-commercially, and license their derivative works on different terms, provided the original work is properly cited, appropriate credit is given, any changes made indicated, and the use is non-commercial. See: http://creativecommons.org/licenses/by-nc/4.0/.

ORCID iD

Zhenghao Wu http://orcid.org/0000-0001-8468-1234

\section{REFERENCES}

1 Wu F, Zhao S, Yu B, et al. A new coronavirus associated with human respiratory disease in China. Nature 2020;579:265-9.

2 Johns Hopkins Coronavirus Resource Center. Available: https:// coronavirus.jhu.edu/

3 Pan A, Liu L, Wang C, et al. Association of public health interventions with the epidemiology of the COVID-19 outbreak in Wuhan, China. JAMA 2020;323:1915.

4 Kucharski AJ, Russell TW, Diamond C, et al. Early dynamics of transmission and control of COVID-19: a mathematical modelling study. Lancet Infect Dis 2020;20:553-8.

5 Wang D, Hu B, Hu C, et al. Clinical characteristics of 138 hospitalized patients with 2019 novel coronavirus-infected pneumonia in Wuhan, China. JAMA 2020;323:1061.

6 Lai J, Ma S, Wang Y, et al. Factors associated with mental health outcomes among health care workers exposed to coronavirus disease 2019. JAMA Netw Open 2020;3:e203976.

$7 \mathrm{Li} \mathrm{Z,} \mathrm{Ge} \mathrm{J,} \mathrm{Yang} \mathrm{M,} \mathrm{et} \mathrm{al.} \mathrm{Vicarious} \mathrm{traumatization} \mathrm{in} \mathrm{the} \mathrm{general}$ public, members, and non-members of medical teams aiding in COVID-19 control. Brain Behav Immun 2020;88:916-9.

8 Xiao H, Zhang Y, Kong D, et al. The effects of social support on sleep quality of medical staff treating patients with coronavirus disease 2019 (COVID-19) in January and February 2020 in China. Med Sci Monit 2020;26:e923549.

9 Halley MC, Rustagi AS, Torres JS, et al. Physician mothers' experience of workplace discrimination: a qualitative analysis. BMJ 2018;363:k4926.

10 Beverly EA, Hultgren BA, Brooks KM, et al. Understanding physicians' challenges when treating type 2 diabetic patients' social and emotional difficulties: a qualitative study. Diabetes Care 2011;34:1086-8.

11 Hsieh H-F, Shannon SE. Three approaches to qualitative content analysis. Qual Health Res 2005;15:1277-88.

12 Tong A, Sainsbury P, Craig J. Consolidated criteria for reporting qualitative research (COREQ): a 32-item checklist for interviews and focus groups. Int J Qual Health Care 2007;19:349-57.

13 Malterud K. Qualitative research: standards, challenges, and guidelines. Lancet 2001;358:483-8.

14 Maher L, Dertadian G. Qualitative research. Addiction 2018;113:167-72.

15 Treibel TA, Manisty C, Burton M, et al. COVID-19: PCR screening of asymptomatic health-care workers at London Hospital. Lancet 2020;395:1608-10. 
16 Kisely S, Warren N, McMahon L, et al. Occurrence, prevention, and management of the psychological effects of emerging virus outbreaks on healthcare workers: rapid review and meta-analysis. BMJ 2020;369:m1642.

17 World Health Organization. Global surveillance for COVID-19 caused by human infection with COVID-19 virus, 2020. Available: https://www.who.int/publications/i/item/global-surveillance-forcovid-19-caused-by-human-infection-with-covid-19-virus-interimguidance

18 Xiao H, Zhang Y, Kong D, et al. Social capital and sleep quality in individuals who Self-Isolated for 14 days during the coronavirus disease 2019 (COVID-19) outbreak in January 2020 in China. Med Sci Monit 2020;26:e923921.

19 World Health Organization. Social stigma associated with COVID-19. A guide to preventing and addressing social stigma. WHO, 2020. https://www.who.int/docs/default-source/\%20coronaviruse/covid19stigma-guide.pdf

20 Peel JK, Schlachta CM, Alkhamesi NA. A systematic review of the factors affecting choice of surgery as a career. Can J Surg 2018;61:58-67.

21 Kodama S, Saito K, Tanaka S, et al. Cardiorespiratory fitness as a quantitative predictor of all-cause mortality and cardiovascular events in healthy men and women: a meta-analysis. JAMA 2009;301:2024-35.

22 Eftekhar Ardebili M, Naserbakht M, Bernstein C. Healthcare providers experience of working during the COVID-19 pandemic: a qualitative study. Am J Infect Control 2020 doi:10.1016/j.ajic.2020.10.001
23 Liu Q, Luo D, Haase JE, et al. The experiences of health-care providers during the COVID-19 crisis in China: a qualitative study. Lancet Glob Health 2020;8:e790-8.

$24 \mathrm{Xu} Z$, Ye Y, Wang Y, et al. Primary care practitioners' barriers to and experience of COVID-19 epidemic control in China: a qualitative study. J Gen Intern Med 2020;35:3278-84.

25 Sun N, Wei L, Shi S, et al. A qualitative study on the psychological experience of caregivers of COVID-19 patients. Am J Infect Control 2020;48:592-8.

26 Zhang Mao-Mao, Niu N, Zhi Xiao-Xu, et al. Nurses' psychological changes and coping strategies during home isolation for the 2019 novel coronavirus in China: A qualitative study. J Adv Nurs 2021;77:308-17.

27 Williams SN, Armitage CJ, Tampe T, et al. Public perceptions and experiences of social distancing and social isolation during the COVID-19 pandemic: a UK-based focus group study. BMJ Open 2020;10:e039334.

28 Fan J, Hu K, Li X, et al. A qualitative study of the vocational and psychological perceptions and issues of transdisciplinary nurses during the COVID-19 outbreak. Aging 2020;12:12479-92.

29 Lehto RH, Stein KF. Death anxiety: an analysis of an evolving concept. Res Theory Nurs Pract 2009;23:23-41.

30 Draper EJ, Hillen MA, Moors M, et al. Relationship between physicians' death anxiety and medical communication and decisionmaking: a systematic review. Patient Educ Couns 2019;102:266-74.

31 Wang C, Horby PW, Hayden FG, et al. A novel coronavirus outbreak of global health concern. Lancet 2020;395:470-3. 